Research

\title{
The prognostic significance of primary tumor size in squamous cell carcinoma of the penis
}

\author{
Kai $\mathrm{Li}^{1}$ - Guang Wu${ }^{1} \cdot$ Caibin Fan ${ }^{1} \cdot$ Hexing Yuan ${ }^{2}$ \\ Received: 23 April 2021 / Accepted: 1 July 2021 \\ Published online: 19 July 2021 \\ (c) The Author(s) 2021
}

\begin{abstract}
Background To evaluate the association of primary tumor size with clinicopathologic characteristics and survival of patients with squamous cell carcinoma of the penis (SCCP).

Methods This study analyzed the data of 1001 patients with SCCP, obtained from the National Cancer Institute Surveillance, Epidemiology, and End Results (SEER) database between 2010 and 2014. The Kaplan-Meier method and the Cox proportional hazards regression model were used to analyze the effects of primary tumor size on overall survival (OS) and penile carcinoma-specific survival (PCSS).

Results Advanced T stage $(P<0.001)$, lymph node metastasis $(P<0.001)$ and distant metastasis $(P=0.001)$ were more frequently associated with SCCP patients with tumor size $\geq 3 \mathrm{~cm}$ than those with tumor size $<3 \mathrm{~cm}$. In Kaplan-Meier analyses, the patients with large tumors $(\geq 3 \mathrm{~cm})$ exhibited an inferior OS and PCSS than those with small tumors $(<3 \mathrm{~cm})$. Moreover, tumor size was identified to be an independent prognostic factor for OS [hazard ratio (HR) $1.665, P<0.001$ ] and PCSS (HR 2.076, P=0.003) of patients with SCCP in multivariate analyses.

Conclusions Large tumor size is associated with adverse clinicopathological characteristics of patients with SCCP. Besides, tumor size represents an independent prognostic factor for OS and PCSS. Therefore, clinical assessment of tumor size as a crucial prognostic factor might be highly beneficial for early intervention in patients with SCCP.
\end{abstract}

Keywords Tumor size · Prognostic value · Squamous cell carcinoma of the penis · Overall survival · Penile carcinomaspecific survival

\section{Introduction}

Penile carcinoma is a relatively rare malignancy, with incidence varying from country to country (Fig. 1) [1, 2]. The etiology of penile carcinoma is multifactorial; however, the incidence of penile carcinoma is particularly high in regions with a high prevalence of human papillomavirus (HPV), and approximately one-third of cases can be attributed to HPV infection [3]. Besides, numerous other etiologic factors including phimosis, chronic inflammation, poor hygiene, balanitis xerotica obliterans, penile trauma, human immunodeficiency virus and tobacco consumption have been identified to increase the risk of developing penile carcinoma $[4,5]$.

Kai Li and Guang Wu contributed equally to this work

Caibin Fan, Furology@163.com; $\bowtie$ Hexing Yuan, YHXurology@163.com |'Department of Urology, The Affiliated Suzhou Hospital of Nanjing Medical University, Suzhou Municipal Hospital, Gusu School, Nanjing Medical University, 26 Daoqian Road, Suzhou 215000, Jiangsu Province, People's Republic of China. ${ }^{2}$ Department of Urology, First Affiliated Hospital of Soochow University, 188 Shizi Road, Suzhou 215000, Jiangsu Province, People's Republic of China. 


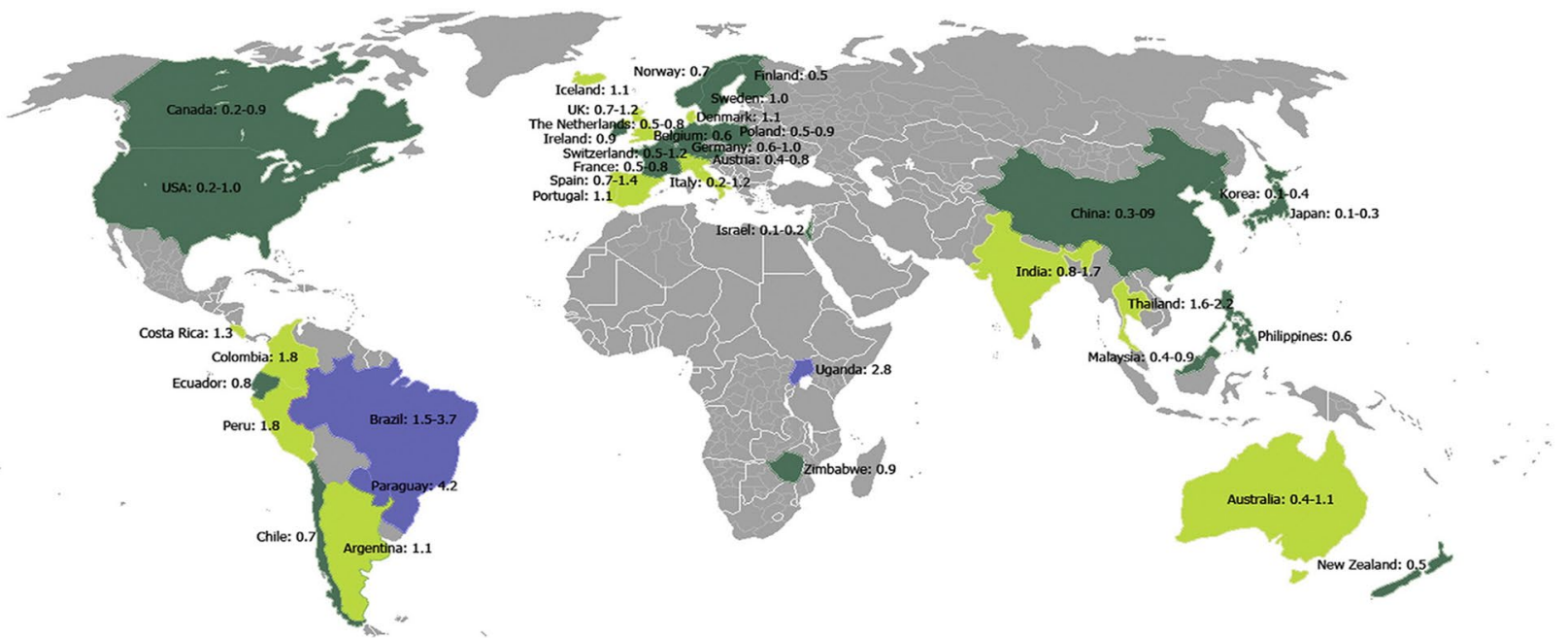

Fig. 1 The incidence of penile cancer in various regions of the world. Blue areas represent high incidence; light green areas represent moderate morbidity; dark green areas represent low morbidity (reported incidence in brackets). Reused by permission from: Chaux A and Cubilla $\mathrm{AL}[1]$

Squamous cell carcinoma of the penis (SCCP) is the predominant histological type of penile carcinomas [6, 7]. It usually occurs in men between the ages of 50 and 70 years [8]. The majority of lesions occur on the glans (48\%), followed by the prepuce (21\%), both glans and prepuce (15\%), coronal sulcus $(6 \%)$, and shaft $(<2 \%)$ [9]. Although the majority of cases are limited when diagnosed, approximately $25 \%$ of SCCP patients may have regional (inguinal and/ or pelvic) lymph node metastasis and nearly $4 \%$ may have a distant disease [10]. Once metastasis occurs, the prognosis could be very poor and the mortality rate increases [3]. Furthermore, Novara et al. reported that men with SCCP, if remain untreated, usually die within 2 years post-diagnosis, due to uncontrollable locoregional lesion or distant metastases [4]. Currently, organ preservation approaches remain the treatment of choice for most patients with early tumors. However, for invasive tumors, a partial or radical penectomy is the oncological gold standard therapy [3, 11].

An increasing number of studies have been conducted to identify significant prognostic factors for SCCP. Wiechno et al. reported that the presence of metastases in the lymph nodes significantly predicted a worse prognosis for patients with SCC of the penis [12]. Sanchez et al. found that histologic subtypes of SCCP played a crucial role in determining risk for patients' survival [13]. Besides, several other prognostic indicators, including histological grade, lymphovascular embolization and primary tumor stage have been studied [14, 15]. Nevertheless, the prognostic value of tumor size in SCCP remains elusive. Moreover, the tumor size of SCCP is not considered as an important criterion for classification in the Tumor-Node-Metastasis (TNM) staging system, developed by the Union for International Cancer Control (UICC). Using the Surveillance, Epidemiology, and End Results (SEER)-registered database, the present study aimed to evaluate the relationship between primary tumor size and clinicopathologic characteristics and survival of men with SCCP.

\section{Methods}

\subsection{Study population}

We extracted the clinical data of patients with SCCP diagnosed between 2010 and 2014 from the SEER database. The inclusion criteria were as follows: (1) Penile carcinoma with codes 8051, 8052 and 8070-8075 were considered as SCCP as defined by International Classification of Diseases for Oncology, 3rd Edition (ICD-O-3) [16]; (2) Patients underwent surgery and had histopathologically confirmed diagnosis of SCCP; and (3) Patients with available data on age, T stage, lymph nodes status, grade, distant metastasis, regional lymph nodes removed, surgery and tumor size. The selection procedure is showed in Fig. 2. Ultimately, a total of 1001 eligible patients were included. 
As the data were de-identified, this study was considered exempt from approval by the Institutional Review Board. Also, the requirement for informed consent from patients was considered waived [17].

\subsection{Study variables}

The primary endpoints of the study were overall survival (OS) and penile carcinoma-specific survival (PCSS). OS was defined as the time period from the date of SCCP diagnosis to the date of death from any cause or the date of the last follow-up [7]. PCSS was defined as the time interval from the date of diagnosis to the date of death from SCCP or the last follow-up date for censoring [7]. Covariates for each case included age, clinical and histological characteristics (T stage, lymph nodes status, grade, distant metastasis, regional lymph nodes removed, surgery, and tumor size). A previous study reported that the 5-year cure rates of patients with penile cancer lesions more than $3 \mathrm{~cm}$ was 50 per cent, while patients with lesions smaller than $3 \mathrm{~cm}$ had higher the 5-year cure rates [18]. So, according to these findings, $3 \mathrm{~cm}$ was determined as the cut-off value for tumor size in this study. TNM stages were determined according to the American Joint Committee on Cancer (AJCC) 7th edition staging system. The survival cut-off date was December 31, 2014 in this study. The cause of death was determined from the death certificate.

\subsection{Statistical analysis}

The association between categorical variables was determined using the chi-square test. The Kaplan-Meier method was used to calculate survival probabilities, and the differences were assessed with the log-rank test. Significantly associated variables identified by Kaplan-Meier analyses were then entered into a Cox proportional hazards regression model for multivariate analysis, yielding hazard ratios (HR) and 95\% confidence intervals (Cl). Two-sided $p$-values of $<0.05$ were considered statistically significant. All statistical analyses were performed using SPSS 17.0 (IBM Corporation, Armonk, NY, USA). All data were extracted using SEER*Stat Software version 8.3.5 (Information Management Sercives, Inc. Calverton, MD, USA).

Fig. 2 Selection procedure

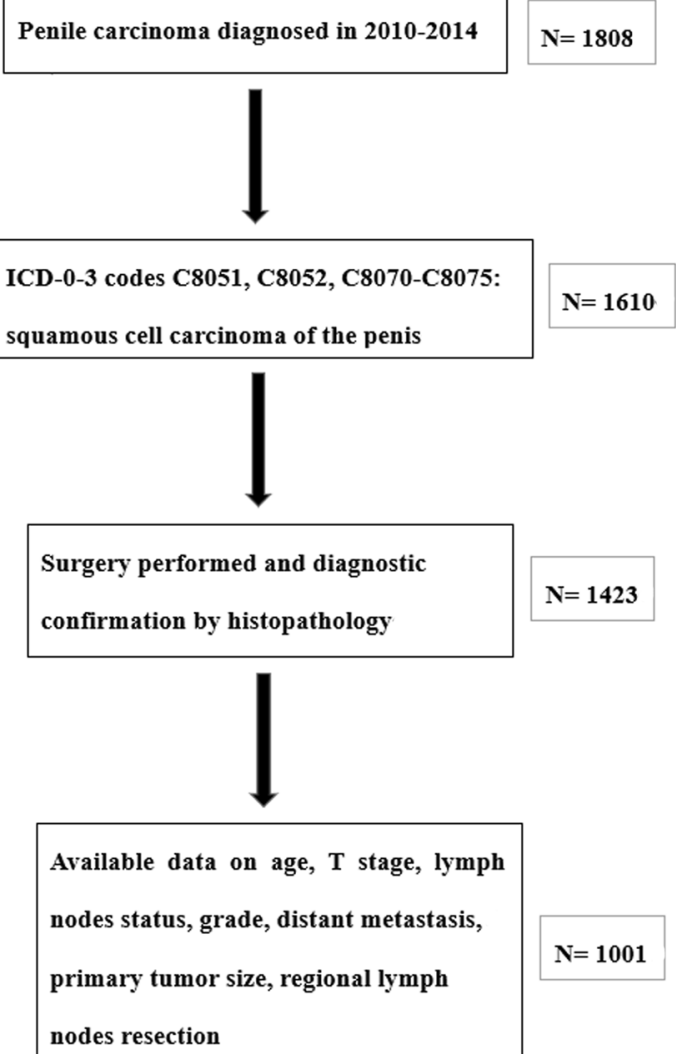




\section{Results}

Overall, a total of 1001 patients with SCCP meeting the eligibility criteria were included in the study. A total of 609 patients with SCCP who did not undergo surgery and did not provide relevant data on age, T stage, lymph nodes status, grade, distant metastasis, regional lymph nodes removed, surgery and tumor size were excluded. A total of 433 (43.3\%) patients exhibited the tumor size $<3 \mathrm{~cm}$, while $568(56.7 \%)$ had tumor size $\geq 3 \mathrm{~cm}$. In this study, the median follow-up period was 17 months (range, 0-59). A total of 276 (27.6\%) patients with SCCP died in this study.

As presented in Table 1, we analyzed the association of tumor size with clinicopathological characteristics. The results revealed that advanced T stage $(T 1 b-T 4)(P<0.001)$, lymph node metastasis $(P<0.001)$ and distant metastasis $(P=0.001)$ were more significantly associated with SCCP patients with tumor size $\geq 3 \mathrm{~cm}$ than those with tumor size $<3 \mathrm{~cm}$. However, no statistically significant differences in age $(P=0.454)$ or grade $(P=0.068)$ were found between the two groups. Moreover, regional lymph nodes removed $(P<0.001)$ and radical surgery $(P<0.001)$ were more frequently performed in patients with tumor size $\geq 3 \mathrm{~cm}$.

In Kaplan-Meier analyses, patients with tumor size $\geq 3 \mathrm{~cm}$ exhibited significantly lower OS and PCSS than those with tumor size $<3 \mathrm{~cm}(P<0.001$ for both, Table 2$)$. We also found that $T$ stage $(P<0.001$ for both, Table 2$)$, lymph nodes status $(\mathrm{P}<0.001$ for both, Table 2$)$, grade $(\mathrm{P}<0.001$ for both, Table 2$)$, distant metastasis $(\mathrm{P}<0.001$ for both, Table 2$)$ and surgery $(P=0.004, P=0.018$, Table 2$)$ were significantly associated with OS and PCSS. Besides, age $(P<0.001$, Table 2$)$ was significantly associated with $O S$, whereas regional lymph nodes removed ( $P=0.046$, Table 2$)$ was significantly correlated with PCSS. Overall, these results indicated that age, T stage, lymph nodes status, grade, distant metastasis, surgery, tumor size, and regional lymph nodes removed were significant prognostics factors for poor survival. Subsequently, these variables were included in the multivariate analyses except surgery, after considering collinearity between the variables.

Moreover, the KM curves of the stratified analyses showed that tumor size $\geq 3 \mathrm{~cm}$ was significantly associated with poorer OS and worse $P C S S$ in patients with age $<65$ years old $(P<0.001$ for both, Fig. $3 A, C)$, age $\geq 65$ years old $(P<0.001, P=0.003$, Fig. 3B, D), Tx-T1a stage ( $P=0.007, P=0.028$, Fig. 4A, C), T1 b-T4 stage $(P=0.001$ for both, Fig. 4B, $D)$, Nx-N0 stage $(P=0.001$,

Table 1 Association of primary tumor size with clinicopathologic characteristics

\begin{tabular}{|c|c|c|c|c|}
\hline $\mathrm{N}(\%)$ variables & All patients & Tumor size $<3 \mathrm{~cm}$ & Tumor size $\geq 3 \mathrm{~cm}$ & $P$ \\
\hline No. of patients & 1001 & 433 & 568 & \\
\hline Age & & & & 0.454 \\
\hline$<65$ & $404(40.4)$ & $169(41.8)$ & $235(58.2)$ & \\
\hline$\geq 65$ & $597(59.6)$ & $264(44.2)$ & $333(55.8)$ & \\
\hline T stage & & & & $<0.001$ \\
\hline $\mathrm{Tx}-\mathrm{T} 1 \mathrm{a}$ & $412(41.2)$ & $239(58.0)$ & $173(42.0)$ & \\
\hline T1b-T4 & $589(58.8)$ & $194(32.9)$ & $395(67.1)$ & \\
\hline Lymph nodes status & & & & $<0.001$ \\
\hline $\mathrm{Nx}-\mathrm{NO}$ & $822(82.1)$ & $391(47.6)$ & $431(52.4)$ & \\
\hline $\mathrm{N} 1-\mathrm{N} 3$ & $179(17.9)$ & $42(23.5)$ & $137(76.5)$ & \\
\hline Grade & & & & 0.068 \\
\hline $\mathrm{G} 1+\mathrm{G} 2$ & $789(78.8)$ & $353(44.7)$ & $436(55.3)$ & \\
\hline $\mathrm{G} 3+\mathrm{G} 4$ & $212(21.2)$ & $80(37.7)$ & $132(62.3)$ & \\
\hline Distant metastasis & & & & 0.001 \\
\hline Mo & $974(97.3)$ & $430(44.1)$ & $544(55.9)$ & \\
\hline M1 & $27(2.7)$ & $3(11.1)$ & $24(88.9)$ & \\
\hline Regional lymph nodes removed & & & & $<0.001$ \\
\hline No & $778(77.7)$ & $366(47.0)$ & $412(53.0)$ & \\
\hline Yes & $223(22.3)$ & $67(30.0)$ & $156(70.0)$ & \\
\hline Surgery & & & & $<0.001$ \\
\hline Non-radical surgery & $964(96.3)$ & $428(44.4)$ & $536(55.6)$ & \\
\hline Radical surgery & $37(3.7)$ & $5(13.5)$ & $32(86.5)$ & \\
\hline
\end{tabular}

Significant values in bold 
Table 2 Kaplan-Meier analyses predicting overall survival and penis cancerspecific survival in 1001 patients with SCCP

\begin{tabular}{|c|c|c|c|c|}
\hline \multirow[b]{2}{*}{ Variables } & \multicolumn{2}{|l|}{ Overall survival, $\%$} & \multicolumn{2}{|c|}{$\begin{array}{l}\text { Penis cancer-specific survival, } \\
\%\end{array}$} \\
\hline & $\begin{array}{l}\text { 3-year probability } \\
\text { (SEM) }\end{array}$ & $P$ & $\begin{array}{l}\text { 3-year probability } \\
\text { (SEM) }\end{array}$ & $P$ \\
\hline Age & & $<0.001$ & & 0.677 \\
\hline$<65$ & $73.6(2.7)$ & & $79.0(2.8)$ & \\
\hline$\geq 65$ & $57.1(2.6)$ & & $77.1(2.9)$ & \\
\hline T stage & & $<0.001$ & & $<0.001$ \\
\hline Tx-T1a & $74.0(2.8)$ & & $90.0(2.4)$ & \\
\hline $\mathrm{T} 1 \mathrm{~b}-\mathrm{T} 4$ & $56.0(2.6)$ & & $69.1(3.0)$ & \\
\hline Lymph nodes status & & $<0.001$ & & $<0.001$ \\
\hline $\mathrm{Nx}-\mathrm{N} 0$ & $68.8(2.1)$ & & $86.3(1.9)$ & \\
\hline $\mathrm{N} 1-\mathrm{N} 3$ & $39.8(4.8)$ & & $43.4(5.9)$ & \\
\hline Grade & & $<0.001$ & & $<0.001$ \\
\hline $\mathrm{G} 1+\mathrm{G} 2$ & $66.5(2.1)$ & & $81.3(2.2)$ & \\
\hline $\mathrm{G} 3+\mathrm{G} 4$ & $51.8(4.4)$ & & $64.4(4.9)$ & \\
\hline Distant metastasis & & $<0.001$ & & $<0.001$ \\
\hline Mo & $64.8(2.0)$ & & $80.2(2.0)$ & \\
\hline M1 & $21.0(9.0)$ & & $22.9(9.7)$ & \\
\hline Regional lymph nodes removed & & 0.364 & & 0.046 \\
\hline No & $63.4(2.2)$ & & $80.7(2.2)$ & \\
\hline Yes & $64.0(4.1)$ & & $70.7(4.4)$ & \\
\hline Surgery & & 0.004 & & 0.018 \\
\hline Non-radical surgery & $64.3(2.0)$ & & $78.5(2.1)$ & \\
\hline Radical surgery & $41.0(11.6)$ & & $65.8(10.7)$ & \\
\hline Tumor size & & $<0.001$ & & $<0.001$ \\
\hline$<3 \mathrm{~cm}$ & $75.5(2.6)$ & & $89.2(2.5)$ & \\
\hline$\geq 3 \mathrm{~cm}$ & $54.4(2.7)$ & & $69.8(2.9)$ & \\
\hline
\end{tabular}

SCCP squamous cell carcinoma of the penis, SEM standard error of mean

Significant values in bold

$P=0.017$, Fig. $5 A, C)$, N1-N3 stage $(P<0.001, P=0.001$, Fig. 5B, D), M0 stage $(P<0.001$ for both, Fig. $6 A, C)$, grade 1-2 $(P<0.001$ for both, Fig. 7A, $C)$, grade 3-4 $(P=0.005, P=0.012$, Fig. 7B, $D)$, non-radical surgery $(P<0.001$ for both, Fig. $8 A, C)$, no regional lymph nodes removed $(P<0.001$ for both, Fig. $9 A, C)$, and regional lymph nodes removed ( $P=0.025, P=0.029$, Fig. 9B, $D)$.

As represented in Table 3, the multivariate Cox proportional hazards analyses revealed that tumor size in patients with SCCP was an independent predictor for both OS (HR 1.665, $\mathrm{P}<0.001$ ) and PCSS (HR 2.076, $\mathrm{P}=0.003$ ). Besides, T stage (HR $1.444, \mathrm{P}=0.016 ; \mathrm{HR} 2.365, \mathrm{P}=0.003)$ and lymph node status (HR 1.809, $\mathrm{P}<0.001 ; \mathrm{HR} 4.595, \mathrm{P}<0.001)$ were also significant independent predictors for OS and PCSS. Notably, age (HR 1.933, P<0.001) and distant metastasis $(H R 2.934, P<0.001)$ were significantly associated with OS, while regional lymph nodes removed (HR $0.513, P=0.009)$ was associated with PCSS based on this model. However, grade (HR 1.197, P $=0.224 ; \mathrm{HR} 1.483, \mathrm{P}=0.067$ ) was not found to be significantly associated with OS or PCSS. 

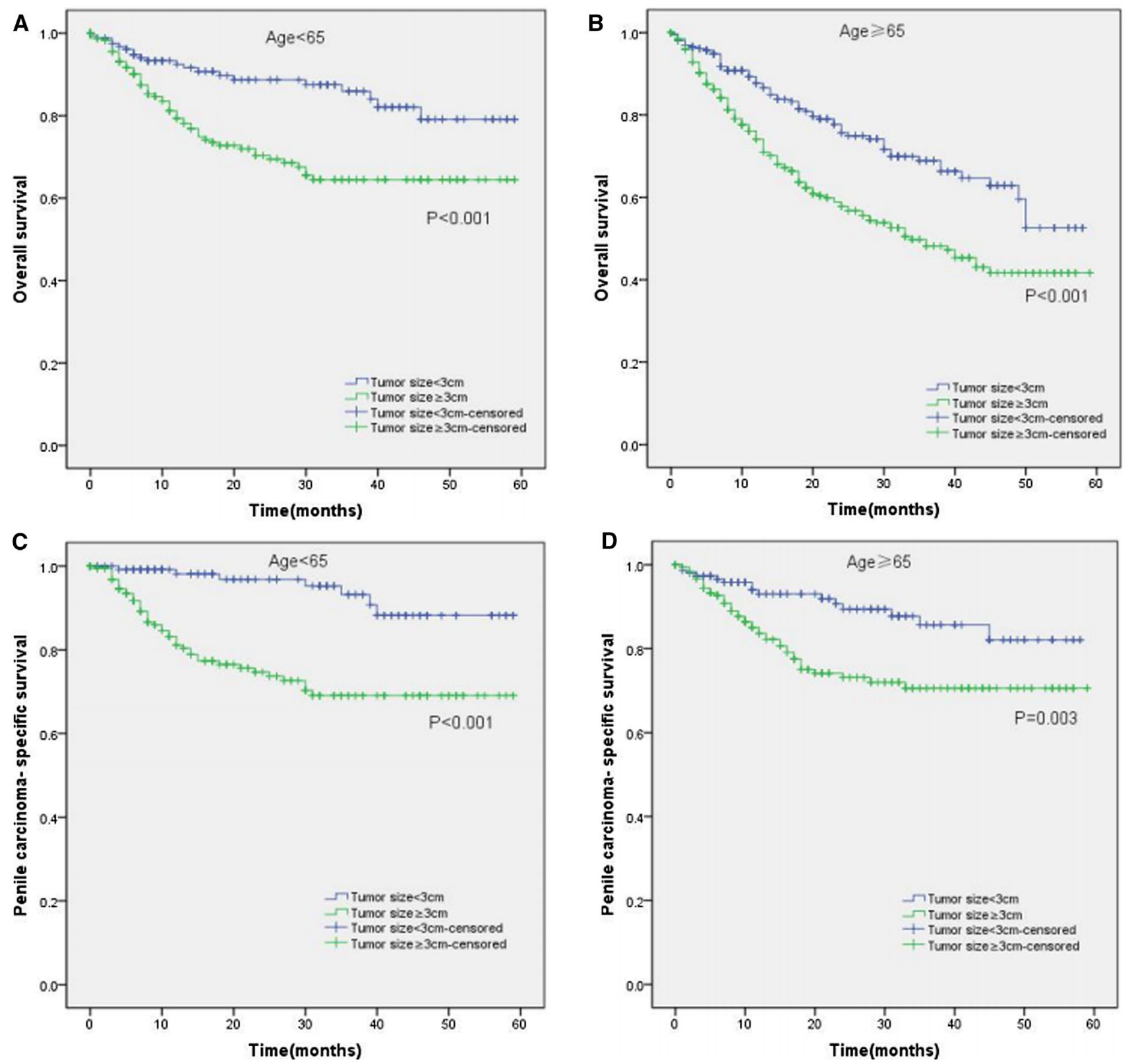

Fig. 3 Kaplan-Meier analyses of overall survival (A, B) and penile carcinoma-specific survival (C, D) between age $<65$ years old group and age $\geq 65$ years old group in patients stratified by tumor size

\section{Discussion}

Squamous cell carcinoma of the penis is a rare but psychologically devastating malignant disease. Indeed, the rarity of this cancer limits the reliability and validity of reported prognostic factors and understanding of its associated risk factors [4]. In this study, we revealed that among the investigated clinicopathological characteristics that can be pre-or intraoperatively evaluated, large tumor size was a poor prognostic factor for SCCP. Therefore, a precise pre- and intra-operative assessment of the tumor size is crucial for improved survival of patients with SCCP. Given this finding, surgeons should take into consideration this important prognostic factor and individualized treatments accordingly.

The present study also indicated that advanced T stage (T1b-T4) was more common in SCCP patients with large tumors. According to the 2009 TNM clinical and pathological classification of penile cancer [19], the tumor invades 

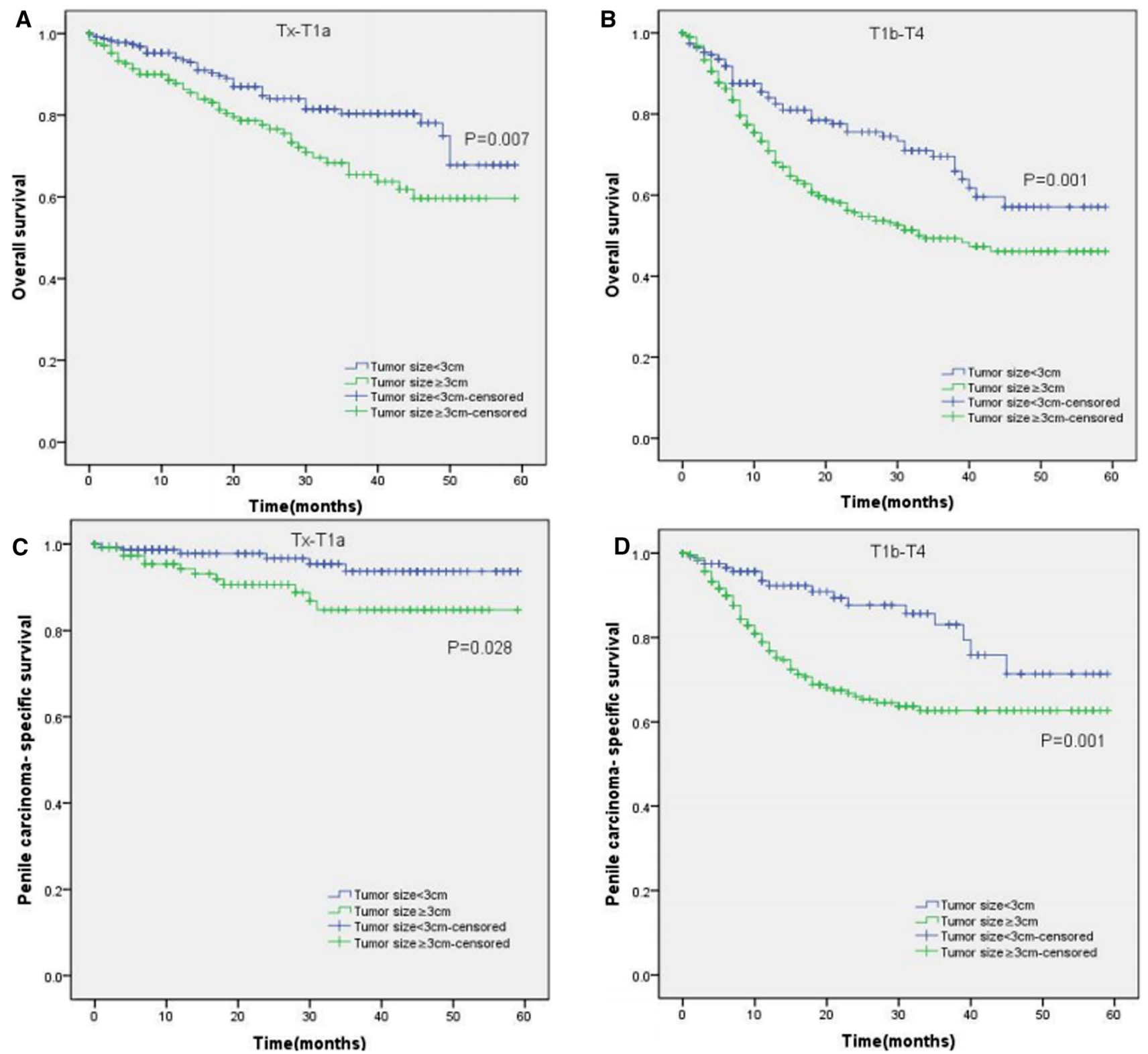

Fig. 4 Kaplan-Meier analyses of overall survival (A, B) and penile carcinoma-specific survival (C, D) between Tx-T1a group and T1b-T4 group in patients stratified by tumor size

subepithelial connective tissue with lymphovascular invasion in the TIb stage. Particularly in carcinomas, lymphovascular involvement often occurs before invasion [20] and usually forebodes advanced-stage disease [21]. Moreover, the lymphovascular invasion has been ascertained to be a significant risk factor for lymph node metastases [4, 22] and distant metastasis [7]. This evidence could explain why lymph node metastasis and distant metastasis were also common in men with large size of SCCP in this study. Similarly, Antonio et al. also suggested that the tumor size of SCCP with node metastasis tended to be larger [23]. Taken together, these findings suggested that large tumors were more likely to be invasive, as they exhibited an increased risk of being presented with advanced T-stage, lymph node metastasis, and distant metastasis. Accumulating studies have documented that lymph node metastasis and depth of invasion into penile anatomic levels are poor prognostic factors for SCCP $[4,12,23,24]$. We have previously reported that distant metastasis was also significantly independently associated with poor OS and PCSS of men with SCCP [7]. Therefore, we hypothesized that SCCP patients with large tumors might exhibit poor prognosis due to the presence of the above-mentioned risk factors. 

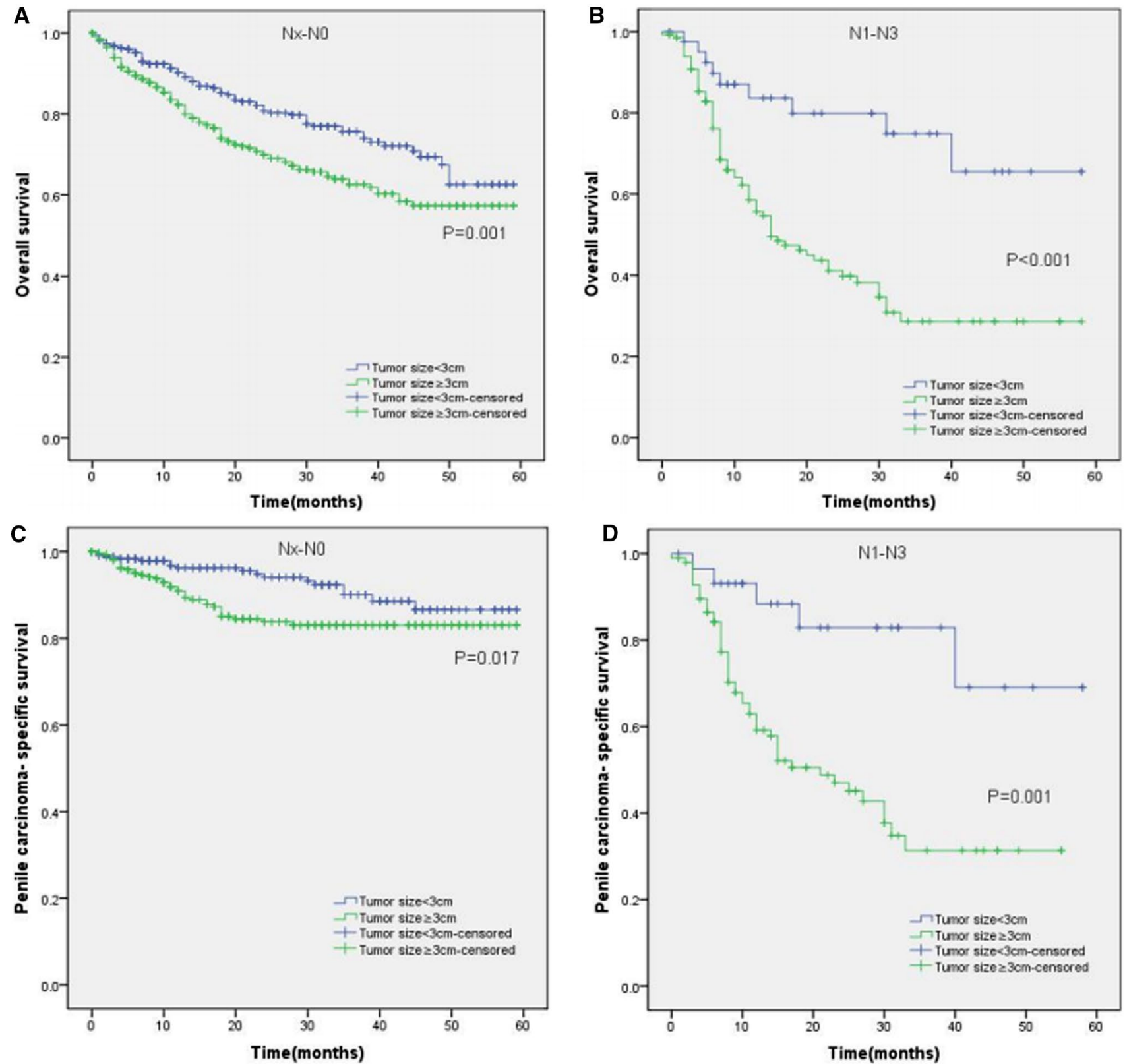

Fig. 5 Kaplan-Meier analyses of overall survival (A, B) and penile carcinoma-specific survival (C, D) between Nx-N0 group and N1-N3 group in patients stratified by tumor size

Furthermore, in our series, the data presented that the patients with large tumors exhibited significantly lower OS and PCSS than those with small tumors in Kaplan-Meier analyses and the stratified analyses. This finding confirmed our hypothesis and was consistent with a previous study conducted by Frederic et al. where they reported the adverse effect of large size of the penile cancer lesion on prognosis was evident from the 5-year survival rates in the 25 determinate cases, and the reason for the adverse effect might be the characteristics that increase the potential for metastasis, such as long duration of the lesion, high aggressiveness, and rapid growth [18]. 

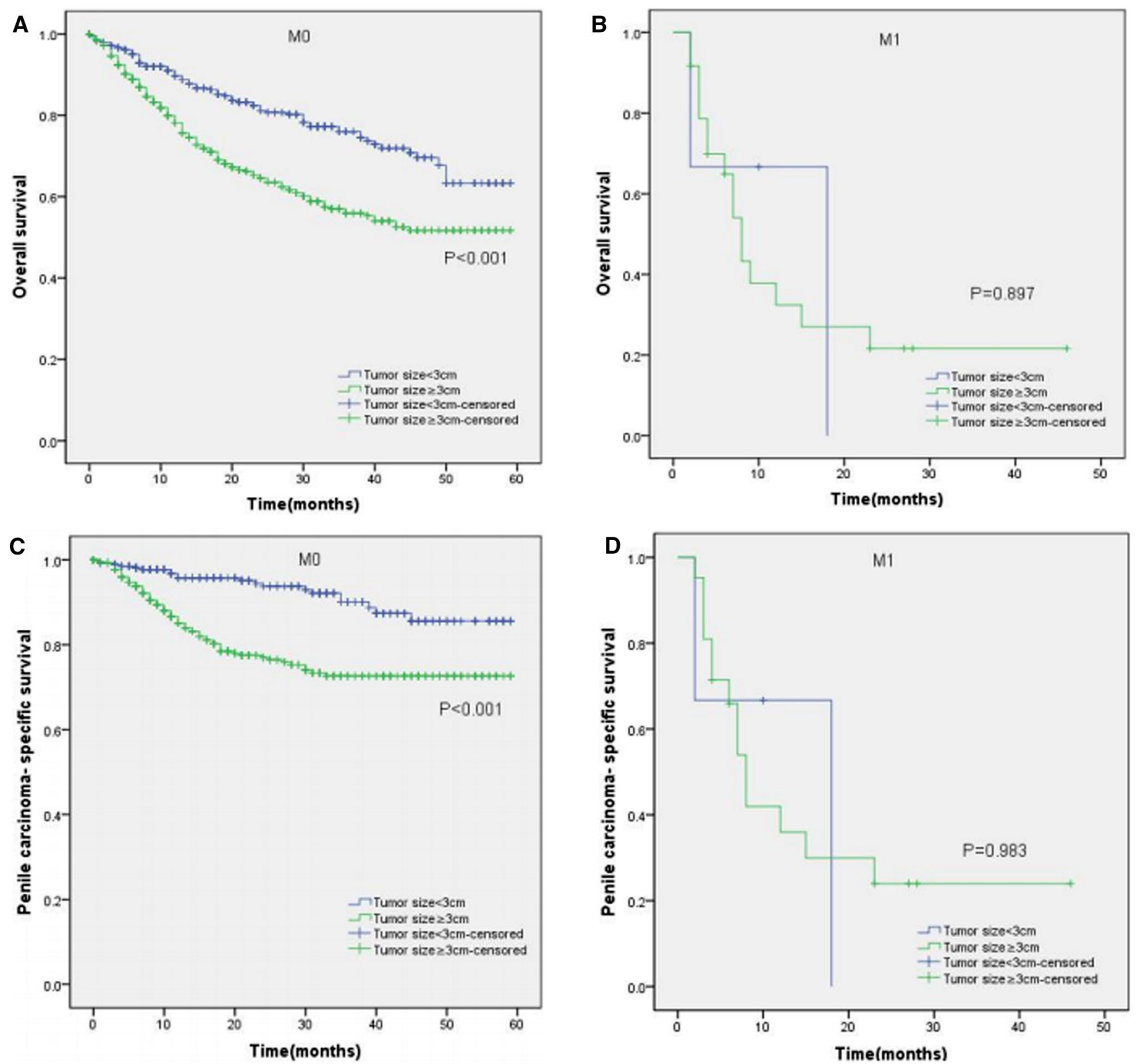

Fig. 6 Kaplan-Meier analyses of overall survival (A, B) and penile carcinoma-specific survival (C, D) between M0 group and M1 group in patients stratified by tumor size

A previous study by Antonio et al. reported no correlation between tumor size of SCCP and patients' outcome [21]. However, the result of this study revealed that tumor size of SCCP was an independent prognostic factor for OS and PCSS in the Cox proportional hazards regression model, after adjusting for age, T stage, lymph nodes status, grade, distant metastasis, and regional lymph nodes removed. Surprisingly, to the best of our knowledge, the present study is the first to report that tumor size is a significant independent prognostic factor for SCCP.

In addition, this study also confirmed that regional lymph nodes removed and radical surgery were more frequently performed in SCCP patients with tumor size $\geq 3 \mathrm{~cm}$ than those with tumor size $<3 \mathrm{~cm}$. In other words, patients with large 

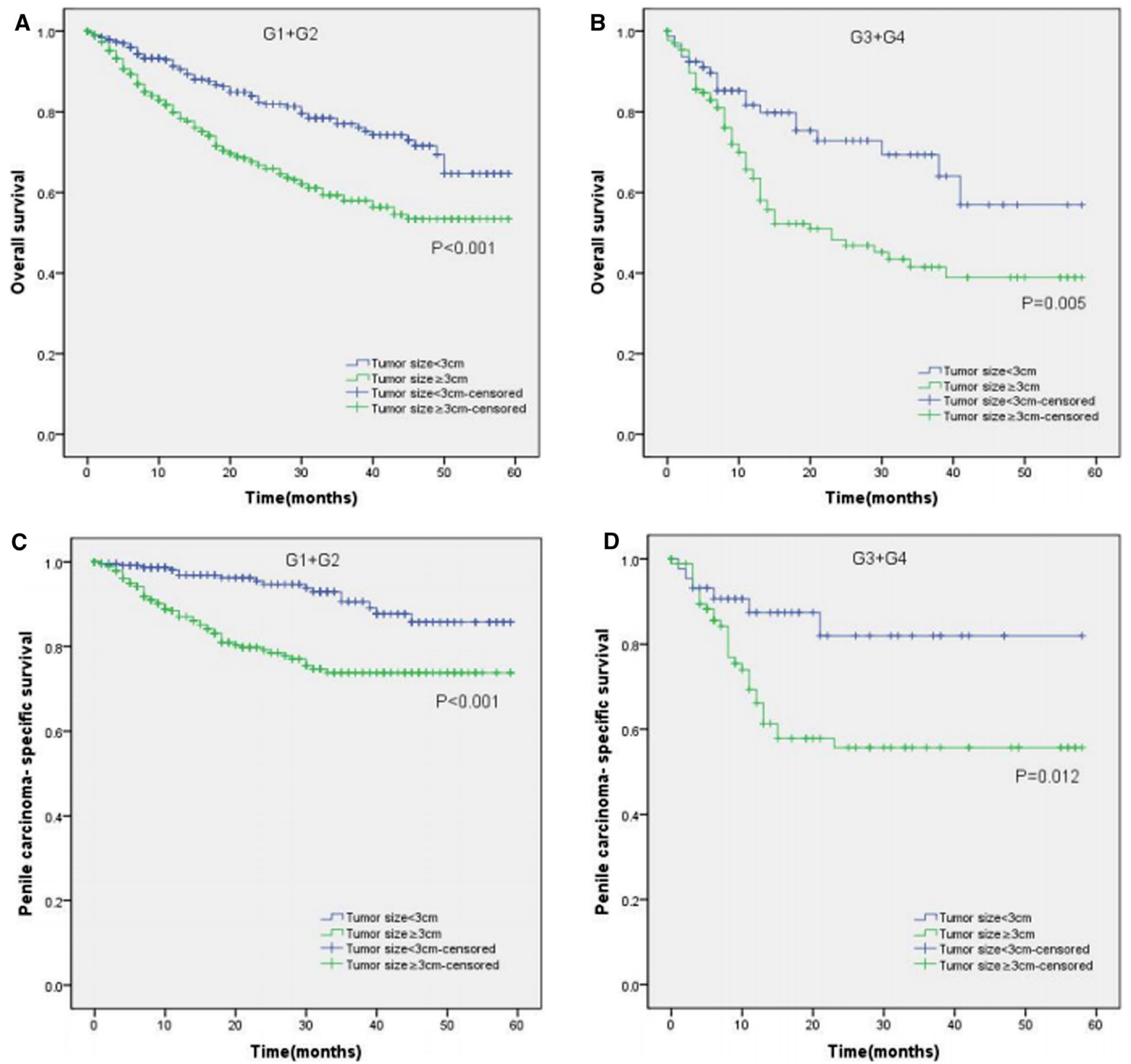

Fig. 7 Kaplan-Meier analyses of overall survival (A, B) and penile carcinoma-specific survival (C, D) between G1 + G2 group and G3 + G4 group in patients stratified by tumor size

size of SCCP are more possibly undergo lymphadenectomy and radical surgery. This study also realized that large-sized tumors are expected to be invasive. Similarly, a previous study reported that for invasive penile cancer, regional lymphadenectomy and amputation were preferred treatment strategies [25].

This study with a large sample size was a population-based assessment, which significantly reduced differences and biases; besides, large sample size was the major advantage of this study compared to previously conducted studies. However, there were several limitations to this study. First, the results of this study were all analyzed retrospectively, and it is highly unlikely that large prospective studies will be organized to validate the prognostic significance of tumor size 

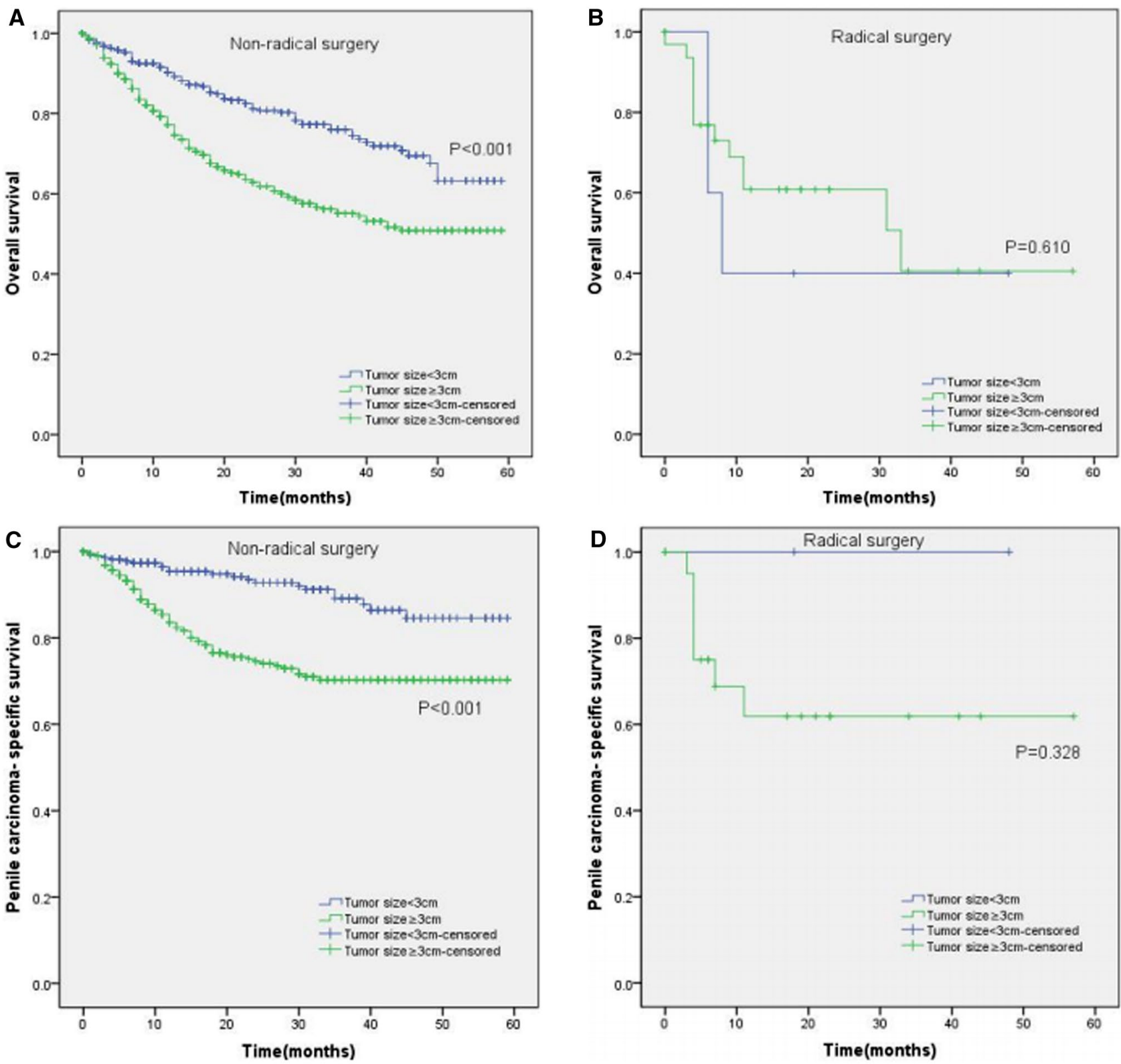

Fig. 8 Kaplan-Meier analyses of overall survival (A, B) and penile carcinoma-specific survival (C, D) between non-radical surgery group and radical surgery group in patients stratified by tumor size

in patients with SCCP. Second, we didn't have access to the medical records of all patients and therefore had to rely on the data of cases recorded in the SEER database. Third, The SEER database does not provide information on the comorbidities that may significantly affect survival rates. Fourth, the population in the SEER database is from the United States, so our findings may not apply to other populations. 

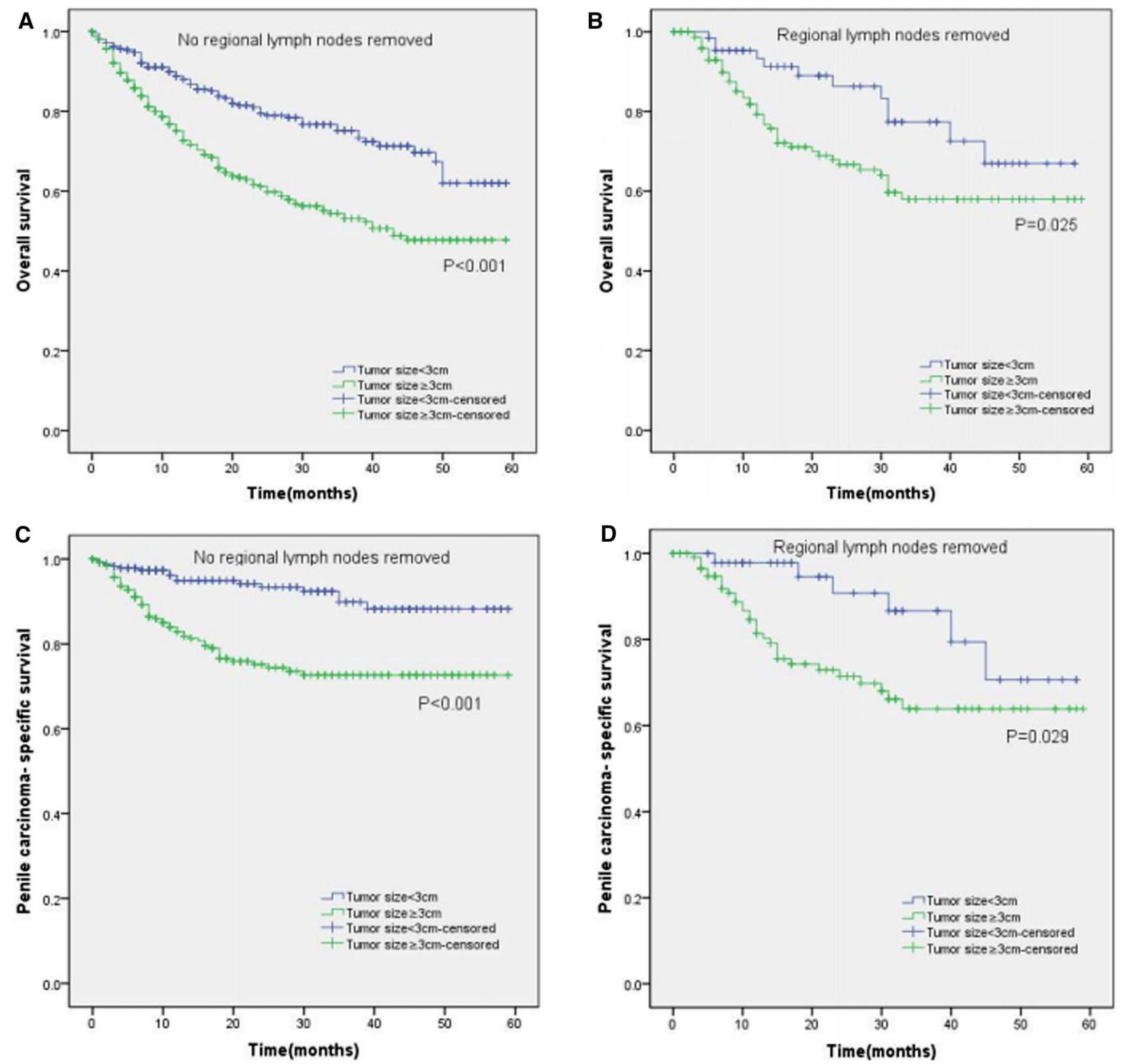

Fig. 9 Kaplan-Meier analyses of overall survival (A, B) and penile carcinoma-specific survival (C, D) between no regional lymph nodes removed group and regional lymph nodes removed group in patients stratified by tumor size

\section{Conclusions}

In conclusion, this SEER-based study revealed that large tumor size was significantly associated with increased risk of SCCP patients being presented with advanced T stage, lymph node metastasis, and distant metastasis. Also, the patients with large tumors exhibited an inferior OS and PCSS than those with small tumors. Besides, tumor size was an independent prognostic factor for OS and PCSS. Therefore, clinical assessment of tumor size as a crucial prognostic factor might be highly beneficial for early intervention in patients with SCCP. 
Table 3 Multivariate Cox regression analyses predicting overall survival and penis cancer-specific survival in 1001 patients with SCCP

\begin{tabular}{|c|c|c|c|c|c|c|}
\hline \multirow[t]{2}{*}{ Variables } & \multicolumn{3}{|c|}{ Overall survival } & \multicolumn{3}{|c|}{ Penis cancer-specific survival } \\
\hline & Hazard ratio & $95 \% \mathrm{Cl}$ & $P$ & Hazard ratio & $95 \% \mathrm{Cl}$ & $P$ \\
\hline Age & 1.933 & $1.472-2.537$ & $<0.001$ & - & - & - \\
\hline T stage & 1.444 & $1.070-1.948$ & 0.016 & 2.365 & $1.338-4.181$ & 0.003 \\
\hline Lymph nodes status & 1.809 & $1.359-2.408$ & $<0.001$ & 4.595 & $2.776-7.604$ & $<0.001$ \\
\hline Grade & 1.197 & $0.896-1.598$ & 0.224 & 1.483 & $0.973-2.261$ & 0.067 \\
\hline Distant metastasis & 2.934 & $1.748-4.922$ & $<0.001$ & 1.760 & $0.918-3.375$ & 0.089 \\
\hline Regional lymph nodes removed & - & - & - & 0.513 & $0.310-0.848$ & 0.009 \\
\hline Tumor size & 1.665 & $1.276-2.172$ & $<0.001$ & 2.076 & $1.278-3.373$ & 0.003 \\
\hline
\end{tabular}

SCCP squamous cell carcinoma of the penis, $\mathrm{Cl}$ confidence intervals

Significant values in bold, "-"= no data

Acknowledgements The authors thank the Surveillance, Epidemiology, and End Results (SEER) database for the data.

Author's contributions $\mathrm{KL}, \mathrm{CBF}$ and $\mathrm{HXY}$ conceived and designed project. $\mathrm{KL}$ and GW collected and analyzed the data. $\mathrm{KL}$, GW, CBF and $\mathrm{HXY}$ wrote the manuscript. All authors read and approved the final manuscript.

Funding This work was supported by Science and Technology Development Program of Suzhou (SYS2018045).

Data availability The web address of SEER database is https://seer.cancer.gov/, and there are no restrictions on the use of this database by non-academics.

\section{Declarations}

Ethics approval and consent to participate For this study, all data were extracted from SEER database. The institutional review board approval was not required for the SEER program of the National Cancer Institute as it utilizes the deidentified public-use database (http://www.uab. edu/research/administration/offices/IRB/FAQs/Pages/PublicDatasets.aspx; http://research.fiu.edu/documents/irb/documents/approvedDa taSets.pdf).

Consent for publication Not applicable.

Competing interests The authors declare that they have no competing interests.

Open Access This article is licensed under a Creative Commons Attribution 4.0 International License, which permits use, sharing, adaptation, distribution and reproduction in any medium or format, as long as you give appropriate credit to the original author(s) and the source, provide a link to the Creative Commons licence, and indicate if changes were made. The images or other third party material in this article are included in the article's Creative Commons licence, unless indicated otherwise in a credit line to the material. If material is not included in the article's Creative Commons licence and your intended use is not permitted by statutory regulation or exceeds the permitted use, you will need to obtain permission directly from the copyright holder. To view a copy of this licence, visit http://creativecommons.org/licenses/by/4.0/.

\section{References}

1. Chaux A, Cubilla AL. Advances in the pathology of penile carcinomas. Hum Pathol. 2012;43(6):771-89.

2. Van Poppel H, Watkin NA, Osanto S, Moonen L, Horwich A, Kataja V. Penile cancer: ESMO clinical practice guidelines for diagnosis, treatment and follow-up. Ann Oncol. 2013;24:115-24.

3. Hakenberg OW, Compérat EM, Minhas S, Necchi A, Protzel C, Watkin N. EAU guidelines on penile cancer: 2014 update. Eur Urol. 2015;67(1):142-50.

4. Novara G, Galfano A, De Marco V, Artibani W, Ficarra V. Prognostic factors in squamous cell carcinoma of the penis. Nat Clin Pract Urol. 2007;4(3):140-6.

5. Spiess PE, Horenblas S, Pagliaro LC, Biagioli MC, Crook J, Clark PE, et al. Current concepts in penile cancer. J Natl Compr Canc Netw. 2013;11(5):617-24.

6. Mentrikoski MJ, Stelow EB, Culp S, Frierson HF, Cathro HP. Histologic and immunohistochemical assessment of penile carcinomas in a north American population. Am J Surg Pathol. 2014;38(10):1340-8.

7. Li K, Sun J, Wei X, Wu G, Wang F, Fan C, et al. Prognostic value of lymphovascular invasion in patients with squamous cell carcinoma of the penis following surgery. BMC Cancer. 2019;19(1):476. 
8. Barnholtz-Sloan JS, Maldonado JL, Pow-sang J, Guiliano AR. Incidence trends in primary malignant penile cancer. Urol Oncol Semin Orig Invest. 2007;25(5):361-7.

9. Marchionne E, Perez C, Hui A, Khachemoune A. Penile squamous cell carcinoma: a review of the literature and case report treated with mohs micrographic surgery. An Bras Dermatol. 2017;92(1):95-9.

10. Richter S, Ruether JD, Wood L, Canil C, Moretto P, Venner P, et al. Management of carcinoma of the penis: consensus statement from the Canadian association of genitourinary medical oncologists (CAGMO). Can Urol Assoc J. 2013;7:E797-811.

11. Audenet F, Sfakianos JP. Psychosocial impact of penile carcinoma. Transl Androl Urol. 2017;6(5):874-8.

12. Wiechno P, Kalinowski T, Itrych B, Sikora-Kupis B, Demkow T, Karwanski M. Prognostic factors in patients undergoing lymphadenectomy for squamous cell carcinoma of the penis. Urol Int. 2014;92(2):194-201.

13. Sanchez DF, Soares F, Alvarado-Cabrero I, Canete S, Fernandez-Nestosa MJ, Rodriguez IM, et al. Pathological factors, behavior, and histological prognostic risk groups in subtypes of penile squamous cell carcinomas (SCC). Semin Diagn Pathol. 2015;32(3):222-31.

14. Soria JC, Fizazi K, Piron D, Kramar A, Gerbaulet A, Haie-Meder C, et al. Squamous cell carcinoma of the penis: Multivariate analysis of prognostic factors and natural history in a monocentric study with a conservative policy. Ann Oncol. 1997;8(11):1089-98.

15. Lopes A, Bezerra AL, Pinto CA, Serrano SV, de MellO CA, Villa LL. p53 as a new prognostic factor for lymph node metastasis in penile carcinoma: analysis of 82 patients treated with amputation and bilateral lymphadenectomy. J Urol. 2002;168(1):81-6.

16. Scosyrev E, Yao J, Messing E. Urothelial carcinoma versus squamous cell carcinoma of bladder: is survival different with stage adjustment? Urology. 2009;73(4):822-7.

17. Yao H, Xie M, Fu S, Guo J, Peng Y, Cai Z, et al. Survival analysis of patients with invasive extramammary paget disease: implications of anatomic sites. BMC Cancer. 2018;18(1):403.

18. Mohs FE, Snow SN, Messing EM, Kuglitsch ME. Microscopically controlled surgery in the treatment of carcinoma of the penis. J Urol. 1985;133(6):961-6.

19. Sobin LH, Gospodarowicz MK, Wittekind C. TNM classification of malignant tumours. 7th ed. Hoboken: Wiley; 2009.

20. Velazquez EF, Soskin A, Bock A, Codas R, Barreto JE, Cubilla AL. Positive resection margins in partial penectomies: sites of involvement and proposal of local routes of spread of penile squamous cell carcinoma. Am J Surg Pathol. 2004;28(3):384-9.

21. Cubilla AL. The role of pathologic prognostic factors in squamous cell carcinoma of the penis. World J Urol. 2009;27(2):169-77.

22. Ornellas AA, Nobrega BL, Wei KCE, Wisnescky A, Da SP, de Santos SA. Prognostic factors in invasive squamous cell carcinoma of the penis: analysis of 196 patients treated at the Brazilian National Cancer Institute. J Urol. 2008;180(4):1354-9.

23. Cubilla AL, Reuter V, Velazquez E, Piris A, Saito S, Young RH. Histologic classification of penile carcinoma and its relation to outcome in 61 patients with primary resection. Int J Surg Pathol. 2001;9(2):111-20.

24. Liu JY, Li YH, Zhang ZL, Yao K, Ye YL, Xie D, et al. The risk factors for the presence of pelvic lymph node metastasis in penile squamous cell carcinoma patients with inguinal lymph node dissection. World J Urol. 2013;31(6):1519-24.

25. Guimarães GC, Rocha RM, Zequi SC, Cunha IW, Soares FA. Penile cancer: epidemiology and treatment. Curr Oncol Rep. 2011;13(3):231-9.

Publisher's Note Springer Nature remains neutral with regard to jurisdictional claims in published maps and institutional affiliations. 